\section{(A) Check for updates}

Cite this: Dalton Trans., 2018, 47 7070

Received 15th November 2017, Accepted 19th April 2018

DOI: $10.1039 / c 7 d t 04310 d$ rsc.li/dalton

\title{
Photocatalytic NO removal over calcium-bridged siloxenes under ultraviolet and visible light irradiation $\dagger$
}

\author{
Haruo Imagawa, (D) *a Xiaoyong Wu, ${ }^{\mathrm{b}}$ Hiroshi Itahara, (D) a Shu Yin, ${ }^{\mathrm{b}}$ \\ Kazunobu Kojima, ${ }^{\text {b }}$ Shigefusa F. Chichibu ${ }^{b}$ and Tsugio Sato ${ }^{b}$
}

\begin{abstract}
Ca-Bridged siloxenes (Ca-siloxenes) composed of two-dimensional siloxene planes with Ca bridging were prepared and their photocatalytic properties for nitrogen oxide (NO) removal were investigated. CaSiloxenes were synthesized via a solid-state metathesis reaction using $\mathrm{TaCl}_{5}$ to extract $\mathrm{Ca}$ from $\mathrm{CaSi}_{2}$ with different $\mathrm{Cl}_{2} / \mathrm{Ca}$ molar ratios of $0.25,1.25$ and 2.5 (CS0.25, CS1.25 and CS2.5, respectively) in an attempt to control the extent of $\mathrm{Ca}$ extraction. Ca-Siloxenes have a wide optical absorption band from the visible to ultraviolet region with absorption edges of 1.5, 2.9, and $3.1 \mathrm{eV}$ for CS0.25, CS1.25, and CS2.5, respectively. Ca-Siloxenes exhibited photocatalytic activity for $\mathrm{NO}$ removal under irradiation with visible $(\lambda>$ $400 \mathrm{~nm}(<3.10 \mathrm{eV}))$ and ultraviolet light $(\lambda>290 \mathrm{~nm}(<4.28 \mathrm{eV}))$. The photocatalytic activity was particularly improved by mixing the Ca-siloxene with acetylene black as a conductive material, which might have inhibited the recombination of photogenerated electrons and holes. The mixture of Ca-siloxene and acetylene black exhibited improved photocatalytic activity in the presence of ${ }^{1} \mathrm{O}_{2}$ as one of the active oxygen species formed under ultraviolet light irradiation.
\end{abstract}

\section{Introduction}

Nitrogen oxide (NOx) is known as an air pollutant that is mainly generated from combustion at industrial power plants and in automobiles. Several negative impacts of NOx on the environment have been recognized, such as the formation of acid rain, photochemical air pollution and ozone layer depletion. Therefore, trials to minimize the effects of NOx have been performed, and catalysts have often been applied for NOx removal at the outlet of combustion systems. For example, selective catalytic reduction and lean NOx traps are useful devices for the removal of NOx in automobiles. ${ }^{1-3}$ However, once released to the atmosphere, the removal of NOx is difficult under ambient conditions due to low NOx concentration and energy sources required for the purification and regeneration of conventional catalysts.

The use of photocatalysts is one possible method to reduce NOx under ambient conditions with the use of sunlight irradiation as a natural resource. $\mathrm{TiO}_{2}$ is the most common

\footnotetext{
${ }^{a}$ Toyota Central R\&D Labs., Inc., 41-1 Yokomichi, Nagakute, Aichi, 480-1192 Japan. E-mail: e1152@mosk.tytlabs.co.jp

${ }^{b}$ Institute of Multidisciplinary Research for Advanced Materials, Tohoku University, 2-1-1 Katahira, Aoba-ku, Sendai 980-8577, Japan

$\dagger$ Electronic supplementary information (ESI) available: X-ray diffraction data and apparent quantum efficiency of Ca-siloxenes. See DOI: 10.1039/c7dt04310d
}

photocatalyst $^{4}$ and effective for photocatalytic NOx removal, ${ }^{5}$ and other materials such as perovskite-type oxides have also been investigated. ${ }^{6,7}$ Silicon-based materials have been investigated for hydrogen production by water splitting; ${ }^{8-11}$ however, the application of Si-based materials to NOx removal is rare. ${ }^{12}$

In our previous study, we reported a novel calcium-bridged siloxene (Ca-siloxene) produced via a convenient solid-state metathesis reaction with an ethanol wash (Scheme 1). ${ }^{13,14}$ In this synthesis, $\mathrm{Ca}$ is extracted from layered $\mathrm{CaSi}_{2}$ with the help of $\mathrm{TaCl}_{5}$ as a $\mathrm{Cl}$ source to form $\mathrm{CaCl}_{2}$, while maintaining partial Ca-bridging between Kautsky-type siloxene planes ${ }^{15,16}$ with $\mathrm{Si}_{6}$ rings connected through $\mathrm{Si}-\mathrm{O}-\mathrm{Si}$ bridges. The presence of Kautsky-type siloxene planes was determined using Raman and Fourier transform-infrared spectroscopy measurements, which showed $\mathrm{Si}_{6}$ rings in Si-based planes and those connected through $\mathrm{Si}-\mathrm{O}-\mathrm{Si}$ bridges, respectively. ${ }^{13}$ Ca-Bridging

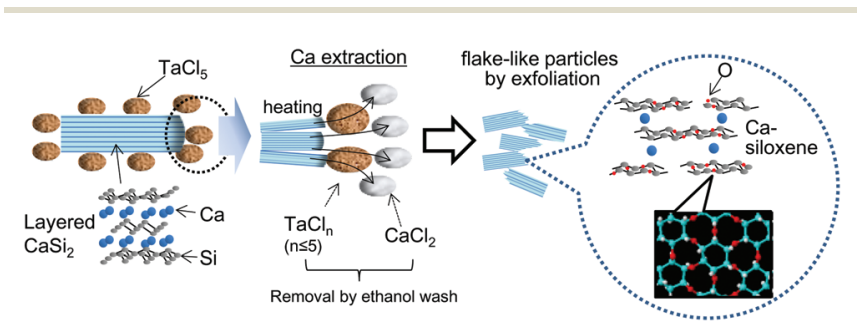

Scheme 1 The solid state reaction employed for Ca-siloxene synthesis. 
in Ca-siloxenes was characterized using the X-ray absorption fine structure, which showed the presence of Si-Ca bonding. ${ }^{13}$ The extent of Ca-extraction and the amount of the resulting Ca-bridging are controlled by variation in the $\mathrm{TaCl}_{5}$ concentration, and both primary and secondary particles become smaller with increased pore volumes as the $\mathrm{Cl}_{2} / \mathrm{Ca}$ molar ratio is increased by fragmentation. ${ }^{13,14}$

Ca-Siloxenes had advantages over conventional Kautskytype siloxenes. For example, the structural stability of Ca-siloxene based on its Ca-bridging was confirmed to be responsible for its stable charge and discharge performance as a Li-ion battery anode. ${ }^{14}$ A similar phenomenon for stability by ion intercalation has also been reported in $2 \mathrm{D}$ materials such as graphene and $\mathrm{g}-\mathrm{C}_{3} \mathrm{~N}_{4}$ for enhancing the interlayer van der Waals force ${ }^{17,18}$ for photocatalysis. ${ }^{19,20}$ In addition, it has been suggested that Ca-siloxene had a tunable direct bandgap energy that is dependent on the amount of Ca-bridging. ${ }^{13}$

A bare Ca-siloxene was reported to exhibit photocatalytic NO removal; ${ }^{12}$ however, its compositional dependence was not examined. It was also implied that the addition of metallic particles may enhance the photocatalytic activity of the bare Casiloxene. $^{12}$ Herein, we report a systematic investigation of these points; the Ca-siloxenes are characterized with respect to optical and electrical properties by variation in the extent of Ca extraction in the synthesis step and the amount of conductive additives. The photocatalytic NO removal by Ca-siloxenes and the effect of conductive additives on the photocatalytic performance under ultraviolet and visible light irradiation are also discussed as a potential application. Chemiluminescence emission measurements for phosphorescence decay are also conducted to deduce a possible reactive species for photocatalytic NO removal.

\section{Experimental}

\subsection{Synthesis of Ca-siloxenes ${ }^{13}$}

Ca-Siloxenes were synthesized using $\mathrm{Cl}_{2} / \mathrm{Ca}$ molar ratios of $0.25,0.5$ and 2.5 (CS0.25, CS1.25 and CS2.5, respectively). In the synthesis, $\mathrm{CaSi}_{2}$ (3.2, 1.6 and $0.32 \mathrm{mmol}$ for CS0.25, CS1.25 and CS2.5, Rare Metallic Co.) and $\mathrm{TaCl}_{5}$ (0.32 mmol, Wako Pure Chemical) were used as starting materials. A mixture of $\mathrm{CaSi}_{2}$ and $\mathrm{TaCl}_{5}$ was placed in boron nitride (BN) crucibles. These mixtures were calcined at $215{ }^{\circ} \mathrm{C}$ for $5 \mathrm{~h}$ at a heating rate of $100{ }^{\circ} \mathrm{C} \mathrm{h}^{-1}$. The mixtures packed in the $\mathrm{BN}$ crucibles were subsequently placed in sealed stainless steel cells (inner volume of $10 \mathrm{~cm}^{3}$ ). The products were then washed with anhydrous ethanol to remove the by-product $\mathrm{CaCl}_{2}$ and excess $\mathrm{TaCl}_{5}$ or their derivatives, before drying under vacuum at $80{ }^{\circ} \mathrm{C}$. Each step in the synthesis was conducted under an $\mathrm{Ar}$ atmosphere. Kautsky-type siloxene as a reference sample was synthesized by the oxidation of $\mathrm{CaSi}_{2}$ with $\mathrm{HCl}$ aqueous solution, as previously described in the literature, ${ }^{15,16}$ and $\mathrm{CaSi}_{2}$ was also used as a reference sample. To examine the effects of mixing conductive materials in the samples, Ca-siloxene/acety- lene black $(\mathrm{AB})$ mixtures with mass ratios of 99/1, 95/5, 90/10, and 70/30 were prepared.

\subsection{Characterization of Ca-siloxenes}

The crystalline structures of Ca-siloxenes were investigated using X-ray diffraction (XRD; Rigaku RINT-TTR). Ultraviolet (UV)/visible absorption spectra were acquired with a spectrometer (JASCO V-670) over a $2 \mathrm{~mm}$ diameter of each sample in the diffuse reflectance mode from 200 to $2500 \mathrm{~nm}$ at room temperature under air. Optical bandgap energy values were derived from Tauc plots ${ }^{21}$ of the associated absorption data processed under the Kubelka-Munk function, ${ }^{22}$ based on the following eqn (1)-(3):

$$
\begin{gathered}
F\left(R_{\infty}\right)=\left(1-R_{\infty}\right)^{2} / 2 R_{\infty}=K / S \\
R_{\infty}=R_{\infty}(\text { sample }) / R_{\infty}(\text { standard sample }), \\
\left(F\left(R_{\infty}\right) h \nu\right)^{1 / n}=A\left(h \nu-E_{\mathrm{g}}\right)
\end{gathered}
$$

where $R_{\infty}$ is the absolute reflectance, $K$ is the absorption coefficient, $S$ is the scattering coefficient, $h \nu$ is the photon energy, $n$ is determined according to the transition mode, $A$ is a coefficient, and $E_{\mathrm{g}}$ is the optical bandgap or the absorption edge. $\mathrm{BaSO}_{4}$ was used as a standard sample, and $n=1 / 2$ was applied for direct allowed transitions, as suggested for $\mathrm{Ca}$ siloxenes. $^{12,13}$

The electrical conductivity of the samples was evaluated using a two-probe method with pelletized specimens at room temperature under air. These samples were uniaxially pressed at $8 \mathrm{MPa}$ under DC current application.

The scanning electron microscopy (SEM) image of CS0.25 with $10 \mathrm{wt} \%$ of acetylene black was obtained for morphology characterization, using a Hitachi S-3600N scanning electron microscope.

\subsection{Photocatalytic properties}

The photocatalytic performance of the samples was measured based on the NO concentration at the outlet of the reactor using a NOx analyzer (Yanaco, ELC-88A) in the same manner as published in the literature. ${ }^{7,12,23,24}$ The reactor volume was $373 \mathrm{~cm}^{3}$ and the size of the sample glass holder was $20 \times 15 \times$ $0.5 \mathrm{~mm}$. A constant flow rate of $200 \mathrm{~mL} \mathrm{~min}^{-1}$ of $1 \mathrm{ppm} \mathrm{NO}$ 50 vol\% air with $\mathrm{N}_{2}$ balance was applied for the reaction. Before light irradiation, the reactor with samples was purged under a constant flow of 1 ppm NO-50 vol\% air with $\mathrm{N}_{2}$ balance for $10 \mathrm{~min}$ to achieve diffusion and adsorption balance. Light was irradiated using a $450 \mathrm{~W}$ high-pressure mercury lamp using wavelengths of $\lambda>290 \mathrm{~nm}(<4.28 \mathrm{eV})$ or $>400 \mathrm{~nm}(<3.10 \mathrm{eV})$ with filtering out the UV emission. NO conversion was calculated based on the following eqn (4):

$$
\text { NO conversion }(\%)=100 \times C_{\mathrm{NO}} / C_{\mathrm{NO} \text {-feed }}
$$

where $C_{\mathrm{NO}}$ is the NO concentration measured using a NOx analyzer at the outlet of the reactor and $C_{\mathrm{NO}}$-feed is the feed NO concentration measured before light irradiation. Durability 
tests were conducted by alternately switching UV light $(\lambda>$ $290 \mathrm{~nm}(<4.28 \mathrm{eV}))$ on and off for $1 \mathrm{~h}$ each.

The apparent quantum efficiency was calculated based on the following eqn (5): ${ }^{24}$

$$
\Phi(\%)=100 \times F_{\mathrm{NO}} \alpha_{\lambda} / P_{\lambda} S A_{\lambda},
$$

where $F_{\mathrm{NO}}\left(\mu \mathrm{mol} \mathrm{s}{ }^{-1}\right)$ is the NO amount rate in the feed gas, $\alpha_{\lambda}$ is the NO conversion of samples $(\%), P_{\lambda}\left(\mu \mathrm{mol} \mathrm{s}{ }^{-1}\right)$ is the light intensity on the surface of the sample holder $(\lambda>290 \mathrm{~nm}$ : $\left.1139.8\left(\mu \mathrm{mol} \mathrm{s}^{-1}\right),>400 \mathrm{~nm}: 846.7\left(\mu \mathrm{mol} \mathrm{s}^{-1}\right)\right), S$ is the surface area of the sample holder $\left(1.28 \times 10^{-3} \mathrm{~m}^{2}\right)$, and $A_{\lambda}$ is the average light absorption ratio of samples at different light wavelengths based on the UV/visible absorption spectra.

The phosphorescence decay profile of singlet oxygen $\left({ }^{1} \mathrm{O}_{2}\right)$ at a wavelength of $634 \mathrm{~nm}$ was measured after UV light $(\lambda=$ $375 \mathrm{~nm}$ ) irradiation for $5 \mathrm{~s}$ using a multi-luminescence spectrometer (Tohoku Electric Ind., MLA-GOLDS). The data were obtained by subtracting the luminous intensity of $\lambda>640 \mathrm{~nm}$ from that of $\lambda>620 \mathrm{~nm}$ using two different cutoff filters.

\section{Results and discussion}

\subsection{Characterization of Ca-siloxenes for optical and conductive properties}

After the reaction of $\mathrm{CaSi}_{2}$ with $\mathrm{TaCl}_{5}$, the synthesized samples exhibited broad peaks in the region from 25 to $40^{\circ}$ due to the formation of an amorphous phase (Fig. S1†). Although CS0.25 contained a crystalline phase derived from unreacted $\mathrm{CaSi}_{2}$, broad peaks became dominant in CS1.25 and CS2.5, which suggests the fragmentation of layered $\mathrm{CaSi}_{2}$ by $\mathrm{Ca}$ extraction and simultaneous exfoliation during synthesis. ${ }^{13}$ Thus, CS0.25 is composed of a mixture of Ca-siloxene particles and remaining crystalline $\mathrm{CaSi}_{2}$ particles, of which the average molar ratio of $\mathrm{Ca}$ to $\mathrm{Si}$ is $0.61: 2 .{ }^{14}$ On the other hand, CS1.25 and CS2.5 are mainly composed of Ca-siloxene particles with average Ca : Si molar ratios of $0.27: 2$ and $0.09: 2$, respectively. ${ }^{14}$

The UV/visible absorption spectra of Ca-siloxenes and Kautsky-type siloxene measured in the diffuse reflectance mode are shown in Fig. 1(A). Absorption spectra were measured from $200 \mathrm{~nm}(6.20 \mathrm{eV})$ to provide more accurate spectra in the UV region in contrast to those measured from $300 \mathrm{~nm}(4.13 \mathrm{eV})$ in our previous work. ${ }^{13}$ All Ca-siloxenes had a characteristic broad absorption band ranging from the UV to visible light region with a clear peak at less than $250 \mathrm{~nm}$ and a shoulder and/or a peak at around $400 \mathrm{~nm}$, which may be preferable for photocatalytic reactions from visible to ultraviolet light irradiation. All the Ca-siloxene samples exhibited semiconducting characteristics due to the Ca-extraction synthesis, in contrast to metallic $\mathrm{CaSi}_{2}$. According to the Tauc plots produced with the assumption of a direct transition (Fig. 1(B)), the absorption edges were increased with the $\mathrm{Cl}_{2} / \mathrm{Ca}$ molar ratio during the synthesis step, and were determined to be 1.5 , 2.9, and $3.1 \mathrm{eV}$ for CS0.25, CS1.25, and CS2.5, respectively. Siloxene has layered 2D Si-based planes composed of $\mathrm{Si}_{6} \mathrm{O}_{3} \mathrm{H}_{6}$ with $\mathrm{Si}_{6}$ rings connected through $\mathrm{Si}-\mathrm{O}-\mathrm{Si}$ bridges. ${ }^{15,16}$ It has
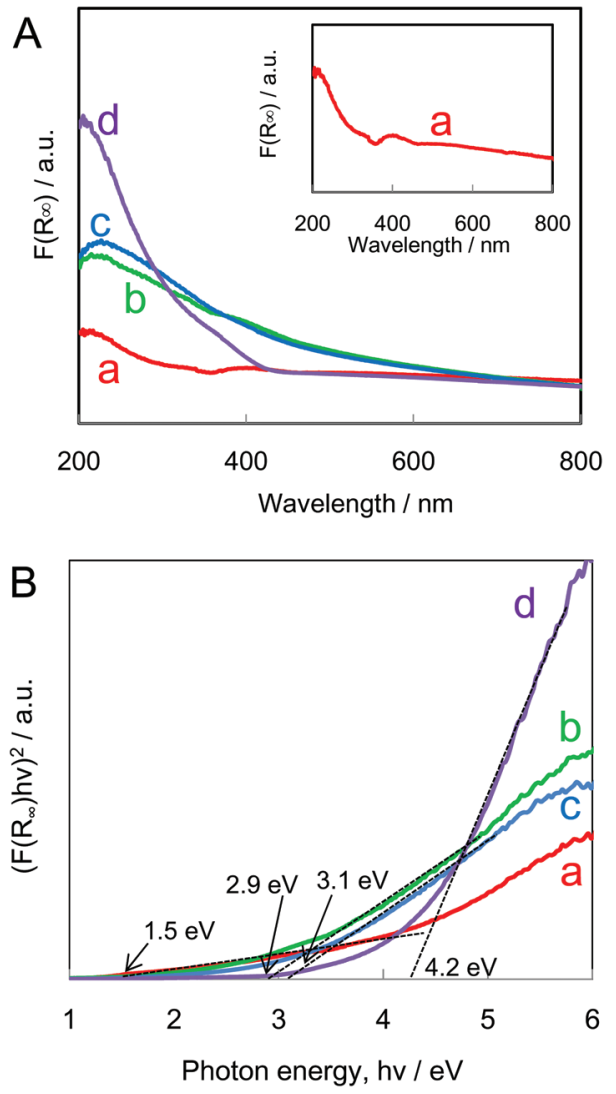

Fig. 1 (A) UV/visible spectra of Ca-siloxenes and (B) Tauc plots based on UV/visible spectral data: (a) CS0.25, (b) CS1.25, (c) CS2.5, and (d) Kautsky-type siloxene. Inset in (A): enlarged UV/visible spectra of CSO.25.

been reported that the siloxene structure exhibits a direct optical transition due to the presence of oxygen $(\mathrm{O})$ atoms in Si planes with the $\sigma-n$ mixing of $\mathrm{Si} \sigma$ electrons and O lone-pair electrons, unlike amorphous $\mathrm{Si}$ (a-Si) or polysilane structures. $^{25}$ The lowest unoccupied conduction band composed of Si planes is reduced by the electron withdrawing properties of $\mathrm{O}$ atoms, and the highest occupied valence band is formed by O lone-pair electrons, which leads to the broadening of the bandgap. In the case of Ca-siloxenes, the amount of $\mathrm{O}$ atoms increased with the extent of $\mathrm{Ca}$ extraction according to the $\mathrm{Cl}_{2}$ / Ca ratio during the synthesis step: $\mathrm{Ca}_{1.8} \mathrm{Si}_{6} \mathrm{O}_{1.5}$ for CS0.25 and $\mathrm{Ca}_{0.3} \mathrm{Si}_{6} \mathrm{O}_{2.8}$ for CS2.5. ${ }^{13}$ Therefore, it would be possible to control the bandgap energy of the Ca-siloxene according to the amount of incorporated $\mathrm{O}$ atoms. The optical band gap energy of the Kautsky-type siloxene was determined to be $4.2 \mathrm{eV}$, which was larger than those previously reported $(2.5-2.9 \mathrm{eV})$ in the literature. ${ }^{16,25}$ The measurements in the previous studies were typically conducted in light of less than $4.13 \mathrm{eV}(300 \mathrm{~nm})$ because these Si-based materials were considered to primarily absorb light below $\mathrm{ca} .4 \mathrm{eV}{ }^{13}$ However, the previous study showed that similar Si-based materials could absorb light with higher photon energies of up to $c a .6 \mathrm{eV} .{ }^{12}$ The density of states generally show a sharp increase at photon energies 
higher than that of the absorption edge; however, density of states with slight tailing at lower energy are often observed in the case of doped materials or impurity fluctuations. The adsorption edge is derived by the extrapolation of the linear region of the Tauc plots observed at higher photon energy. Thus, photon energies of up to $6.20 \mathrm{eV}(200 \mathrm{~nm})$ were used for clarification in the present study, which corresponds to a widening of the measured energy by $c a .2 \mathrm{eV}$, and the impact at lower energy was reduced. The optical band gap energy observed in this study for Ca-siloxene and the Kautsky-type siloxene would be more accurate than those of previous studies. The UV/visible spectra of the Ca-siloxenes also contain broad tailing at less than ca. $4 \mathrm{eV}$, especially in CS1.25 and CS2.5, in contrast to the conventional Kautsky-type siloxenes. One of the reasons for this Urbach tail feature may be due to the amorphous structure of Ca-siloxenes with inconsistent particle size and composition. ${ }^{26}$

Fig. 2(A) shows the electrical conductivity of Ca-siloxenes with Ca-extraction to various extents. The conductivity is almost inversely proportional to the extent of Ca-extraction in the Ca-siloxenes, and the conductivity of CS0.25 was $0.64 \mathrm{mS}$ $\mathrm{cm}^{-1}$, which was the highest electrical conductivity of all the Ca-siloxenes examined. The conductivities of CS1.25 and CS2.5 were $c a$. 0.5 and $0.05 \mu \mathrm{S} \mathrm{cm}{ }^{-1}$, respectively. Therefore, some conductive materials, such as metal particles ${ }^{12}$ and carbon nanotubes, ${ }^{27}$ may assist the construction of an electron pathway in the photocatalytic reaction that inhibits the recombination of photogenerated electrons and holes, and that improves catalytic activity. ${ }^{12,27}$ The electrical conductivity of the mixture of Ca-siloxenes and $\mathrm{AB}$ as a conductive material is shown in Fig. 2(B). The conductivity was increased with the amount of the $\mathrm{AB}$ additive and reached $0.1 \mathrm{~S} \mathrm{~cm}^{-1}$ at $10 \mathrm{wt} \%$ or more. Fig. 2(C) shows the SEM image of CS0.25 with $10 \mathrm{wt} \%$ of $\mathrm{AB}$. Almost consistent mixture of Ca-siloxene secondary particles with a relatively larger

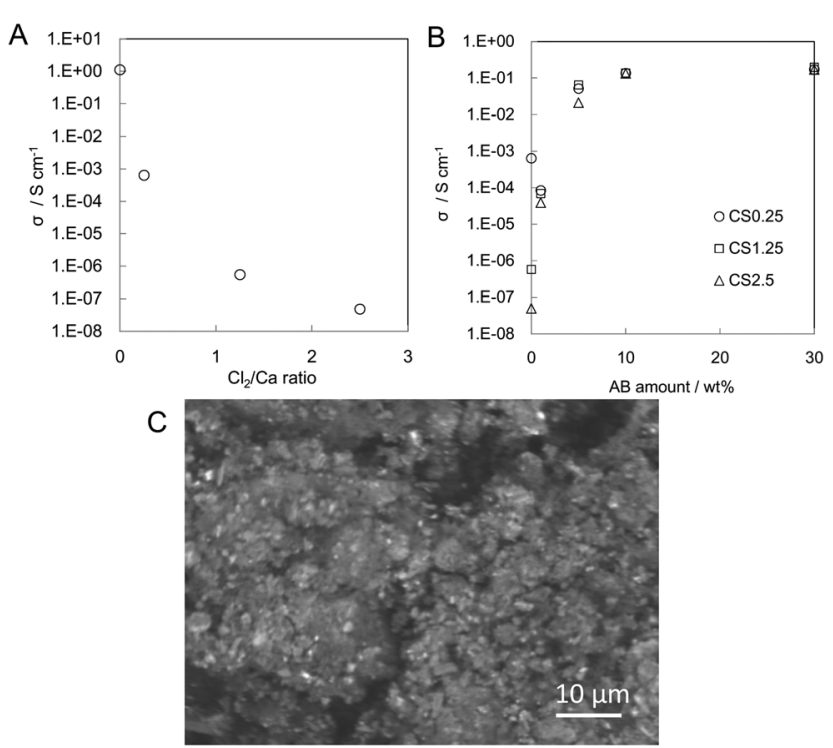

Fig. 2 Electrical conductivity of (A) Ca-siloxenes as a function of $\mathrm{Cl}_{2} / \mathrm{Ca}$ ratio, (B) the mixture of $\mathrm{Ca}$-siloxene and acetylene black $(\mathrm{AB})$ as a function of $A B$ amount, and (C) SEM image of CSO.25 with 10 wt\% of $A B$. size and $\mathrm{AB}$ secondary particles with less than $1 \mu \mathrm{m}$ diameter was observed, which reflect the increased conductivity shown above. Thus, $10 \mathrm{wt} \%$ of $\mathrm{AB}$ seems to be sufficient to cover almost all surfaces of the Ca-siloxene particles. The effect of the addition of conductive materials on the increased activity for NO removal is investigated in the next section.

\subsection{Photocatalytic NO removal by Ca-siloxenes}

Fig. 3(A) shows the NO conversion over Ca-siloxenes under UV light irradiation $(\lambda>290 \mathrm{~nm}(<4.28 \mathrm{eV}))$. Photocatalytic NO
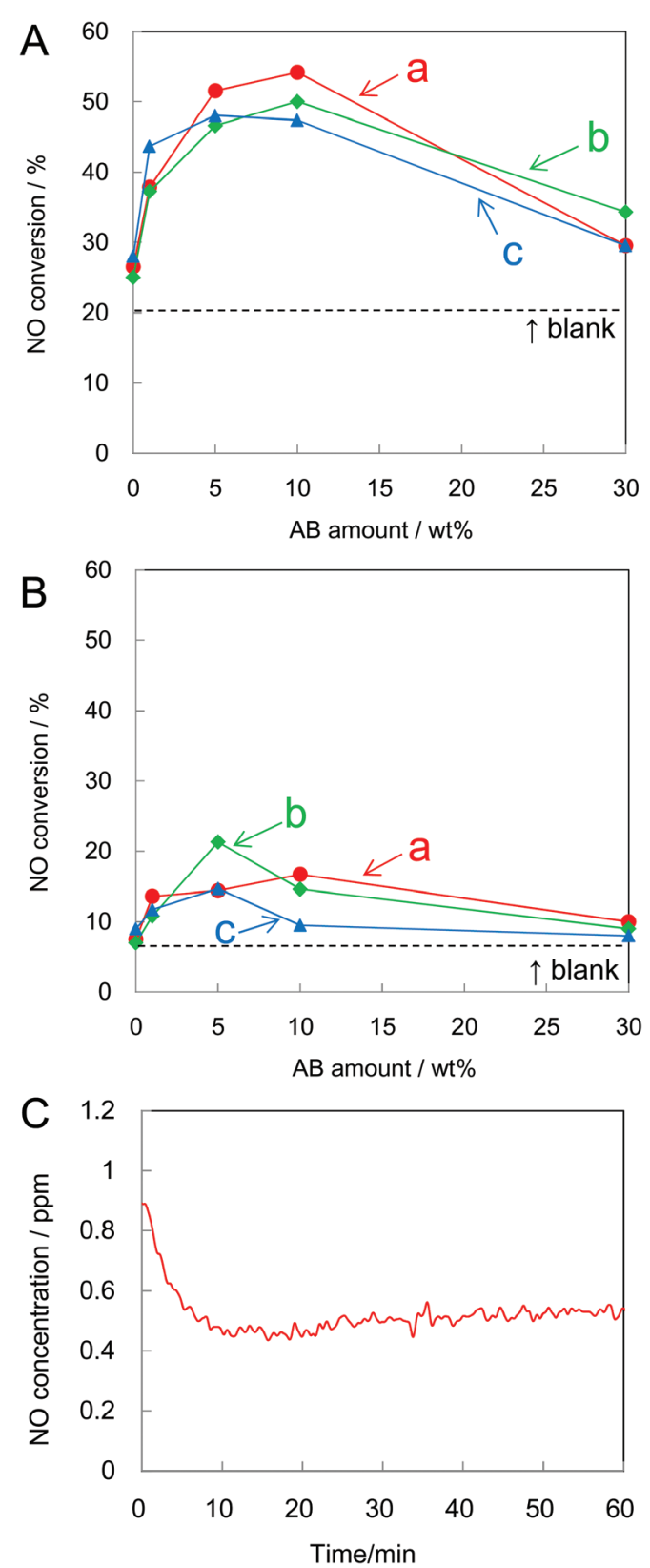

Fig. 3 NO conversions of Ca-siloxenes irradiated at (A) $\lambda>290 \mathrm{~nm}$ and (B) $\lambda>400 \mathrm{~nm}$ as a function of acetylene black amount: (a) CSO.25, (b) CS1.25 and (c) CS2.5, and (C) NO conversion of CS0.25 with 10 wt\% of acetylene black as a function of irradiation time at $\lambda>290 \mathrm{~nm}$. 
removal was observed with all the Ca-siloxene samples, and NO conversion was affected by the mixing of $\mathrm{AB}$ with Ca-siloxenes in all the samples. The removal of NO is expected to form $\mathrm{N}_{2}$ and $\mathrm{HNO}_{3}$, as often reported with $\mathrm{TiO}_{2}$ catalysts, with the aid of a small amount of water in air. ${ }^{24,28,29}$

$\mathrm{NO}$ conversion was increased with the amount of $\mathrm{AB}$ up to $10 \mathrm{wt} \%$, and the maximum NO conversion was observed for the photocatalysts containing $10 \mathrm{wt} \% \mathrm{AB}$. This tendency corresponds to the electrical conductivity of the Ca-siloxene and $\mathrm{AB}$ mixtures. The low electrical conductivity of Ca-siloxene may cause the recombination of photogenerated electrons and holes, which results in low photocatalytic performance. As discussed in section 3.1, all Ca-siloxene particles were brought into contact with the addition of $10 \mathrm{wt} \% \mathrm{AB}$, and therefore the highest photocatalytic performance was achieved. On the other hand, the NO conversion of all samples mixed with $30 \mathrm{wt} \% \mathrm{AB}$ showed a decrease in photocatalytic performance. $\mathrm{AB}$ itself has no photocatalytic activity and thus the decrease in the amount of Ca-siloxene in the samples corresponds to the decrease in NO conversion over the samples with $30 \mathrm{wt} \% \mathrm{AB}$. The best photocatalytic performance was observed in CS0.25 with $10 \mathrm{wt} \% \mathrm{AB}$ addition. One reason for this performance was caused by the largest electric conductivity of CS0.25 in all Casiloxenes.

Fig. 3(B) shows the NO conversion of Ca-siloxenes under visible light irradiation $(\lambda>400 \mathrm{~nm}(<3.10 \mathrm{eV}))$. Samples mixed with 2.5-10 wt\% $\mathrm{AB}$ exhibited clear photocatalytic activity for NO removal, although NO conversion under visible light irradiation was less than that under UV light irradiation. The absorption in the visible light region is present in all Ca-siloxenes, as shown in Fig. 1; however, the intensity was not as high as that observed in the UV light region, which resulted in the relatively lower photocatalytic activity.

To confirm the activity change, Fig. 3(C) shows the NO conversion of CS0.25 with $10 \mathrm{wt} \% \mathrm{AB}$ under UV light irradiation for $60 \mathrm{~min}$. The photocatalytic activity was almost constant, and an obvious decrease in activity was not observed, which supports the stability of Ca-siloxenes during the photocatalytic reaction.

The apparent quantum efficiency of samples mixed with $10 \mathrm{wt} \% \mathrm{AB}$ was roughly estimated in Fig. S2. $\dagger$ The apparent quantum efficiency under UV light irradiation $(\lambda>290 \mathrm{~nm})$ was around $0.0065 \%$, which is almost $1 / 4$ of that found in $\mathrm{TiO}_{2}$ species under similar experimental conditions using a mercury lamp. ${ }^{24}$ The apparent quantum efficiency under visible light irradiation $(\lambda>400 \mathrm{~nm})$ was around $0.0017 \%$ for CS2.5 and $0.0028 \%$ for CS0.25.

For photocatalytic NO removal using $\mathrm{TiO}_{2}$, oxygen radicals $\left({ }^{\circ} \mathrm{O}_{2}\right)$ are formed from $\mathrm{O}_{2}$ at the conduction band and hydroxyl radicals $\left({ }^{\circ} \mathrm{OH}\right)$ are formed from $\mathrm{H}_{2} \mathrm{O}$ at the valence band. ${ }^{23}{ }^{1} \mathrm{O}_{2}$ has also been known as one of the active oxygen species formed by the oxidation of ${ }^{\circ} \mathrm{O}_{2}$ through electron transfer at photogenerated holes during photocatalytic oxidation, ${ }^{30}$ and ${ }^{1} \mathrm{O}_{2}$ is also known to have higher energy than ground-state triplet oxygen for the enhancement of photocatalytic NO removal. ${ }^{28}{ }^{1} \mathrm{O}_{2}$ is detectable from the typical dimol emissions at around 634 and $703 \mathrm{~nm}\left({ }^{1} \mathrm{O}_{2}+{ }^{1} \mathrm{O}_{2} \rightarrow 2{ }^{3} \mathrm{O}_{2}+h \nu\right)$, and from the monomol emission at $1270 \mathrm{~nm}\left({ }^{1} \mathrm{O}_{2} \rightarrow{ }^{3} \mathrm{O}_{2}+h \nu\right) .{ }^{28}$ The phosphorescence decay profile at $634 \mathrm{~nm}$ using a cut-off filter after UV light irradiation for $5 \mathrm{~s}$ was measured and the results are shown in Fig. 4. The Ca-siloxenes, especially CS0.25 and CS 2.5, exhibited phosphorescence decay derived from ${ }^{1} \mathrm{O}_{2}$ after UV light irradiation. The mixture of Ca-siloxenes and $\mathrm{AB}$ as a conductive additive may facilitate the oxidation of photogenerated ${ }^{\circ} \mathrm{O}_{2}$ to ${ }^{1} \mathrm{O}_{2}$ at available holes due to the inhibition of the recombination of photogenerated electrons and holes, as reported for nanocomposite powders of $\mathrm{Si}$ nanoflakes and metallic particles. ${ }^{12}$ Therefore, it is suggested that the same active oxygen species as proposed for photocatalysis with $\mathrm{TiO}_{2}$ is also formed with Ca-siloxenes, which leads to $\mathrm{N}_{2}$ and $\mathrm{HNO}_{3}$ formation in the photocatalytic removal of NO.

\subsection{Durability test}

The durability tests of CS0.25 with 10 wt\% of $\mathrm{AB}$ were conducted, and the results are shown in Fig. 5. Photocatalytic activity was almost maintained through the cycles, except for the initial deterioration during the first cycle. A rapid decrease in photocatalytic activity with degradation and deactivation through hydrogen release by hydrolysis has been reported for photocatalysis with siloxene in water. ${ }^{31}$ In the present experiment, such deactivation and fading performance was not observed, although the Ca-siloxene was exposed to air with a small amount of water during this photocatalytic reaction. Furthermore, siloxene has been reported to gradually form dangling bonds under ultraviolet light irradiation associated with structural degradation; ${ }^{26}$ however, photocatalytic activity was almost maintained in the Ca-siloxenes, which implies that structural stability is due to the Ca-bridging of siloxenes. This is required for maintained photocatalytic activity in contrast to the siloxene structure with no bridges connecting the layered Si planes except for van der Waals forces, which allows unexpected cleavage between planes. The initial deterioration at the first cycle is explained as the adsorption of $\mathrm{HNO}_{3}$ on the sample surface, which is formed as a product during the NO

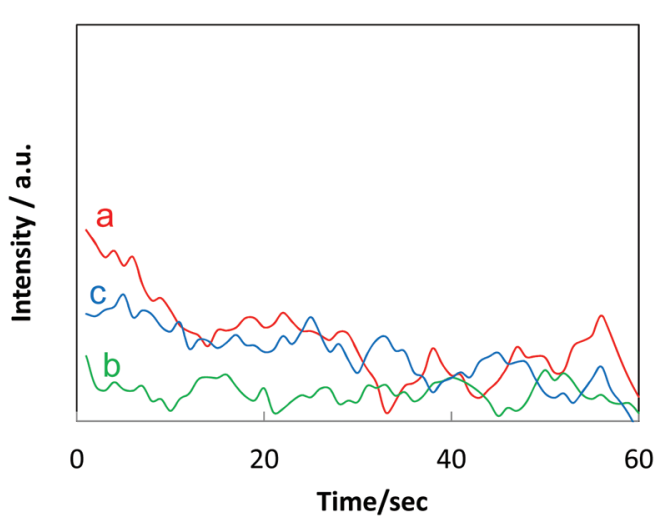

Fig. 4 Phosphorescence decay profile at $634 \mathrm{~nm}$ of ${ }^{1} \mathrm{O}_{2}$ generated at $298 \mathrm{~K}$ in air after $5 \mathrm{~s}$ of UV light irradiation: (a) CS0.25, (b) CS1.25, and (c) CS2.5. 


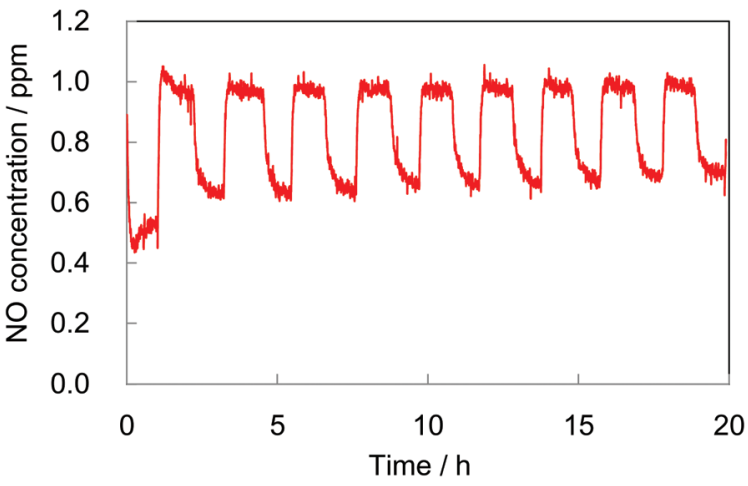

Fig. 5 NO concentration profiles of $\mathrm{CSO} .25$ during the durability test under the irradiation of the ultraviolet light region $(\lambda>290 \mathrm{~nm})$.

removal reaction, which is known to lead to catalyst poisoning in $\mathrm{TiO}_{2} \cdot{ }^{32,33}$ Therefore, the observed initial deterioration is considered to be similar poisoning, although the Ca-siloxenes are not influenced further by $\mathrm{HNO}_{3}$ after the initial poisoning.

\section{Conclusions}

Ca-Siloxenes with two-dimensional siloxene planes formed by Ca-bridging were synthesized, and their optical and electrical properties, and photocatalytic performance for NO removal were investigated. The Ca-siloxenes exhibited a wide and tunable optical absorption band from the visible to ultraviolet region with bandgap energies from 1.5 to $3.1 \mathrm{eV}$. All the Ca-siloxenes exhibited photocatalytic activity for NO removal under visible to ultraviolet light irradiation, which was enhanced by mixing the Ca-siloxene with $\mathrm{AB}$ as a conductive material, probably due to the inhibition of the recombination of photogenerated electrons and holes. The phosphorescence decay profile of the Ca-siloxenes suggested the presence of ${ }^{1} \mathrm{O}_{2}$ as an active oxygen species that enhances photocatalytic NO removal.

\section{Conflicts of interest}

There are no conflicts to declare.

\section{Acknowledgements}

The authors acknowledge Dr Yoshiki Yamazaki of Tohoku University for conducting the diffuse reflectance spectroscopy measurements.

\section{Notes and references}

1 V. I. Pârvulescua, P. Grangeb and B. Delmon, Catal. Today, 1998, 46, 233-316.
2 R. Burch and P. J. Millington, Catal. Today, 1995, 26, 185206.

3 H. Imagawa, T. Tanaka, N. Takahashi, S. Matsunaga, A. Suda and H. Shinjoh, J. Catal., 2007, 251, 315-320.

4 A. Fujishima and K. Honda, Nature, 1972, 238, 37-38.

5 R. Asahi, T. Morikawa, T. Ohwaki, K. Aoki and Y. Tage, Science, 2001, 293, 269-271.

6 D. Wang, J. Ye, T. Kako and T. Kimura, J. Phys. Chem. B, 2006, 110, 15824-15830.

7 H. Li, S. Yin, Y. Wang, T. Sekino, S. W. Lee and T. Sato, J. Catal., 2013, 297, 65-69.

8 F. Dai, J. Zai, R. Yi, M. L. Gordin, H. Sohn, S. Chen and D. Wang, Nat. Commun., 2014, 5, 3605.

9 T. Li, J. Li, Q. Zhang, E. Blazeby, C. Shang, H. Xu, X. Zhang and Y. Chao, RSC Adv., 2016, 6, 7109271099.

10 Y. J. Jang, J. Ryu, D. Hong, S. Park and J. S. Lee, Chem. Commun., 2016, 52, 10221-10224.

11 J. Ryu, Y. J. Jang, S. Choi, H. J. Kang, H. Park, J. S. Lee and S. Park, NPG Asia Mater., 2016, 8, e248.

12 H. Itahara, X. Wu, H. Imagawa, S. Yin, K. Kojima, S. F. Chichibu and T. Sato, Dalton Trans., 2017, 46, 86438648.

13 H. Imagawa, N. Takahashi, T. Nonaka, Y. Kato, K. Nishikawa and H. Itahara, J. Mater. Chem. A, 2015, 3, 9411-9414.

14 H. Imagawa and H. Itahara, Dalton Trans., 2017, 46, 36553660 .

15 H. Kautsky, W. Vogell and F. Oeters, Z. Naturforsch., B: Anorg. Chem. Org. Chem. Biochem. Biophys. Biol., 1955, 10, 597-598.

16 S. Yamanaka, H. Matsu-ura and M. Ishikawa, Mater. Res. Bull., 1996, 31, 307-316.

17 J. Abraham, K. S. Vasu, C. D. Williams, K. Gopinadhan, Y. Su, C. T. Cherian, J. Dix, E. Prestat, S. J. Haigh, I. V. Grigorieva, P. Carbone, A. K. Geim and R. R. Nair, Nat. Nanotechnol., 2017, 12, 546-550.

18 L. Chen, G. Shi, J. Shen, B. Peng, B. Zhang, Y. Wang, F. Bian, J. Wang, D. Li, Z. Qian, G. Xu, G. Liu, J. Zeng, L. Zhang, Y. Yang, G. Zhou, M. Wu, W. Jin, J. Li and H. Fang, Nature, 2017, 550, 380-383.

19 J. Li, W. Cui, Y. Sun, Y. Chu, W. Cen and F. Dong, J. Mater. Chem. A, 2017, 5, 9358-9364.

20 T. Xiong, W. Cen, Y. Zhang and F. Dong, ACS Catal., 2016, 6, 2462-2472.

21 J. Tauc, R. Grigorovici and A. Vancu, Phys. Status Solidi, 1966, 15, 627.

22 P. Kubelka and F. Munk, Z. Tech. Phys., 1931, 12, 593.

23 S. Yin, B. Liu, P. Zhang, T. Morikawa, K. Yamanaka and T. Sato, J. Phys. Chem. C, 2008, 112, 12425-12431.

24 H. Li, S. Yin and T. Sato, Appl. Catal., B, 2011, 106, 586591.

25 K. Takeda and K. Shiraishi, Solid State Commun., 1993, 85, 301-305.

26 H. Hirabayashi, K. Morigaki and S. Yamanaka, J. Phys. Soc. Jpn., 1983, 52, 671-676. 
27 S. Takenaka, T. Arike, H. Matsune and M. Kishida, Appl. Catal., B, 2012, 125, 358-366.

28 Y. Nosaka, T. Daimon, A. Y. Nosaka and Y. Murakami, Phys. Chem. Chem. Phys., 2004, 6, 2917-2918.

29 M. Anpo, in Recent DeVelopments on Visible Light Response Type Photocatalysts, NTS, Tokyo, 2002, p. 9.

30 T. Daimon, T. Hirakawa, M. Kitazawa, J. Suetake and Y. Nosaka, Appl. Catal., A, 2008, 340, 169-175.
31 S. Li, H. Wang, D. Dandan Li, X. Zhang, Y. Wang, J. Xie, J. Wang, Y. Tian, W. Ni and Y. Yi Xie, J. Mater. Chem. A, 2016, 4, 15841-15844.

32 Y. Ishibai, J. Sato, S. Akita, T. Nishikawa and S. Miyagishi, J. Photochem. Photobiol., A, 2007, 177, 106111.

33 T. Ibusuki and K. Takeuchi, J. Mol. Catal., 1994, 88 93-102. 